\title{
Studies on thermal and viscoelastic properties of vinyl ester resin and its composites with glass fiber
}

\author{
André C. Garay ${ }^{1}$, Lucas T. Paese ${ }^{1}$, \\ Jeferson A. Souza ${ }^{2}$, Sandro C. Amico ${ }^{1}$
}

\author{
${ }^{1}$ GCOMP/LAPOL/PPGEM - UFRGS C.P. 91501-970, Porto Alegre/RS. \\ e-mail: andrecechin@yahoo.com.br; lucas_paese@hotmail.com; amico@ufrgs.br \\ ${ }^{2}$ School of Engineering - FURG C.P. 96203-900, Rio Grande/RS. \\ e-mail: jasouza@furg.br
}

\begin{abstract}
Vinyl ester resins are widely used in sandwich composite structures. Because of their good resistance to chemicals, flexibility and easy processing, these sandwich are extensively applied in the marine sector. These composites are typically manufactured by liquid molding processes, especially infusion. In this study, RTM light was used to inject the polymeric resin into the mold cavity, flowing in the space between the impermeable core and the mold walls, where the fibrous medium was. In this process, viscosity, gel time and curing time of the resin are very important parameters. This work addressed the curing and post-curing characteristics of a vinyl ester resin, and also the characteristics of neat and reinforced vinyl ester using dynamic mechanical analysis (DMA). The increase in shear rate did not significantly influence resin viscosity within the studied range. Differential scanning calorimetry showed the efficiency of the post-curing stage, with the decrease in residual enthalpy. With DMA, it was possible to determine gel time and gel temperature, which yielded similar values to those found by the SPI (Society of the Plastics Industry) method, indicating that the simpler SPI method can be reliably used for that.
\end{abstract}

Keywords: Vinyl ester, DMA, RTM light, sandwich composites.

\section{INTRODUÇÃO}

Vinyl ester resins (VER) result from the reaction between bisphenol-A based epoxy oligomers and unsaturated carboxylic acids, such as acrylic or methacrylic acid which provides unsaturated terminal sites [1]]. This resin is one of the most important thermoset polymers that combine the chemical, mechanical and thermal properties of epoxy resins with the fast cure of unsaturated polyester resins (UPRs) [ $\underline{2}-\underline{3}]$.

Composite materials produced with vinyl ester resins and glass fibers are widely used in marine application, such as fishing trawlers, canoes, patrol boats, mine hunters and submarine domes [4]. In many cases, sandwich composite structures are chosen and the easy processing of VER allows the use of liquid molding techniques, such as infusion and RTM light. In these processes, resin is injected into the mold cavity, flowing in the space between the impermeable core of the sandwich and the mold walls, where the fibrous medium is. Since resin flow occurs through long distances, viscosity and gel time of the resin become critical parameters.

The cure of VER plays a vital role in their processing and cure kinetics studies have received much attention. Calorimetry has been used to determine the effect of the initiator concentration and oxygen on the rate of cure [5]. These resins generally contains 30-60\% styrene by weight, which serves as diluents to enhance linear chain extension and to reduce viscosity of the resin, allowing for easy processing and room temperature curing [6]. Styrene also acts as a "bridge" between chains during the cross-link process, that occurs when an initiator opens up double-carbon bonds between vinyl ester and styrene molecules, allowing these free radicals to link and crosslink, resulting in a cured material with high strength and resistance to degradation.

In fact, viscosity of VER, which varies with their molecular weight, the amount of styrene dissolved in it and the temperature [1], is a property of fundamental importance when they are used to produce a thermoset composite using any technique of the liquid molding family, such as resin transfer molding (RTM), 
RTM light (L-RTM) [7] and vacuum assisted resin infusion (VARI). These processes are rapidly becoming very popular because they are ecofriendly, being carried out in closed molds [ [8].

Dynamic mechanical analysis (DMA) has proven a valuable tool for studying the structure of polymers and composites [ $[8,9]$. Study of the glass transition by DMA involves measuring loss and storage modulus of the material in a given oscillation frequency from room temperature to above the glass transition temperature ( $\mathrm{Tg}$ ). During curing of a thermoset polymer, the number of crosslinks increases, consequently, reducing mobility of the molecular segments and increasing $\mathrm{Tg}$ of the material [5]. Once the temperature of the material exceeds the curing temperature, freezing of the reactive groups occurs, preventing further reactions [10]. Post-curing of the polymer also modifies loss and storage modulus, and its $\mathrm{Tg}$, that can be used to verify completeness of the curing reaction.

This work aims to study characteristics of interest of a vinyl ester resin for liquid molding processing, including viscosity variation with shear rate and temperature, gel time and maximum curing temperature. The influence of post-curing on the viscoelastic properties (storage modulus, loss modulus and $\tan \delta$ ) of neat and glass-fiber reinforced resin was also investigated.

\section{EXPERIMENTAL}

\subsection{Materials}

Commercial vinyl ester resin (Derakane momentum 470-300) was used. Commercial grade initiator Butanox M-50 (methyl-ethyl-ketone peroxide, P-MEK), at $1.0-2.0 \%$, catalyzed with $0.6 \%$ of cobalt naphthenate ( $\mathrm{NafCO})$, both in relation to the resin volume. E-glass fiber mats $(350 \mathrm{~g} / \mathrm{m} 2)$ manufactured by Owens Corning were used as reinforcement.

\subsection{Methods}

Viscosity measurements were performed with neat resin (without initiator), from 0 to $40{ }^{\circ} \mathrm{C}$. A Brookfield HBDV-II+C/P viscometer was used with the S51 spindle and at different speeds (20, 30, 50, 60 e $100 \mathrm{rpm})$. Gel time and maximum temperature of cure were determined according to the SPI method together with ASTM D2471. Differential scanning calorimetry (DSC) was carried out in a DSC equipment (model Q20V24.2 Build107), within $20-250^{\circ} \mathrm{C}$ temperature range, under nitrogen atmosphere with a heating rate of $10{ }^{\circ} \mathrm{C} / \mathrm{min}$.

Six types of rigid samples were studied: cured and post-cured neat resin, 4-layers cured/post-cured composite $\left(\mathrm{C}_{4}\right.$ and $\mathrm{C}_{4, \mathrm{pc}}$, respectively), 6-layers cured/post-cured composite $\left(\mathrm{C}_{6}\right.$ and $\mathrm{C}_{6, \mathrm{pc}}$, respectively). The neat resin samples were cast into silicone molds with rectangular geometry (length $\times$ width $\times$ thickness: $35 \times$ $12 \times 4 \mathrm{~mm}$ ). The monolithic composites $\mathrm{C}_{4}$ and $\mathrm{C}_{6}$ were produced by RTM, that comprises the injection of the liquid resin into a closed mold cavity $(320 \times 150 \times 3.6 \mathrm{~mm})$ containing the fiber reinforcement and the subsequent resin cure at room temperature for $24 \mathrm{~h}$, producing a rigid composite. Post-curing at $90{ }^{\circ} \mathrm{C}$ for $6 \mathrm{~h}$ was done in an air-circulation oven (DLAF02-2).

Fiber volume fraction of the composites was determined using the rule of mixtures and also following burning in a muffle furnace (at $560 \pm 25^{\circ} \mathrm{C}$ for $6 \mathrm{~h}$ ) and weighing of the residue. Resin and composite density were calculated using the Archimedes method. Shore D hardness was performed according to ASTM D2240-05 in DWOLTEST durometer, model SD300, with 10 measurements in each sample. Dynamic mechanical analysis (DMA) was performed in a TA Instruments Model 2980 (up to $600{ }^{\circ} \mathrm{C}$ ), at various frequencies $(0.1,1.0,3.0,10,30$ and $100 \mathrm{~Hz})$.

\section{RESULTS AND DISCUSSION}

Figure 1 shows the variation in resin viscosity with temperature and shear rate. Viscosity of the uncured resin decreases within the increase in temperature (Figure 1a) due to the gradual weakening of interaction (van der Waals) forces in the resin. The increase in shear rate did not significantly influence resin viscosity in the studied range (Figure 1b). A high viscosity is an aggravating factor in liquid molding processes, which would be prohibitive for usual processing at low temperatures (in this case, $0-15^{\circ} \mathrm{C}$ ). 

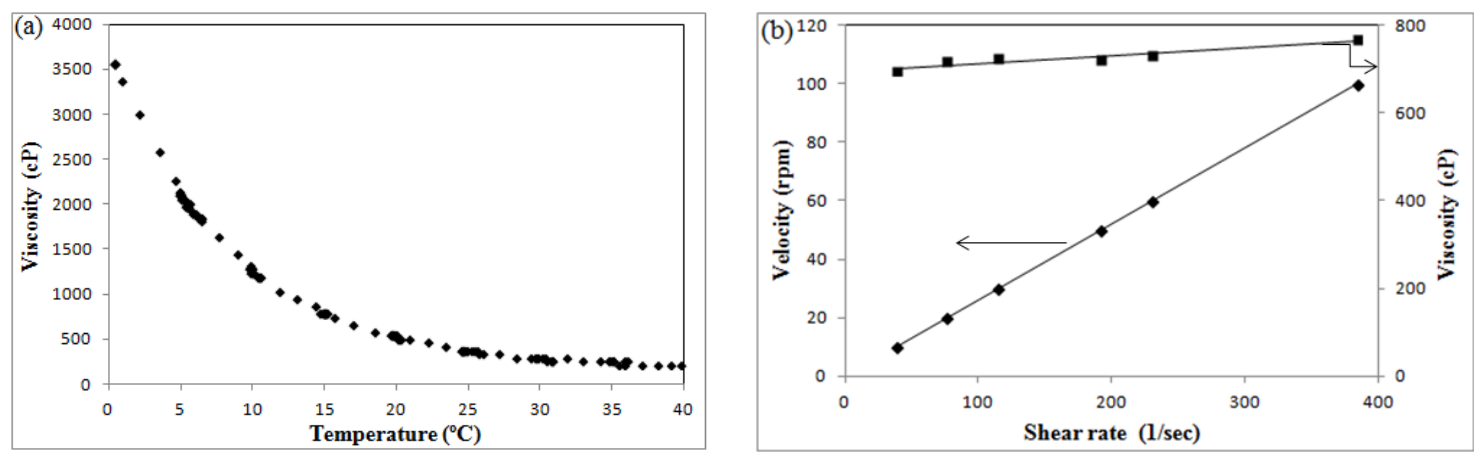

Figure 1: Variation of resin viscosity with temperature (a) and shear rate with velocity and viscosity in $25^{\circ} \mathrm{C}$ (b).

The DSC heat flow curves of the cured and post-cured neat resin are shown in Figure $2 \mathrm{a}$. The cured resin sample shows a large peak (within $\sim 50-160{ }^{\circ} \mathrm{C}$ ), with an associated enthalpy of reaction of $327.3 \mathrm{~J} / \mathrm{g}$ and a $\mathrm{T}_{\mathrm{g}}$ value of $\sim 110^{\circ} \mathrm{C}$. As for the post-cured resin sample, the measured residual enthalpy $(6.9 \mathrm{~J} / \mathrm{g}) \mathrm{was}$ comparatively negligible, and $\mathrm{T}_{\mathrm{g}}$ shifted to $\sim 115^{\circ} \mathrm{C}$. This decrease in the value of enthalpy due to elimination of residual reactions, which leaves almost complete reaction.

The $\tan \delta$ curves obtained with DMA for the cured and post-cured samples are shown in Figure $2 \mathrm{~b}$. The cured sample shows two peaks, at $\sim 65{ }^{\circ} \mathrm{C}$ and $\sim 120{ }^{\circ} \mathrm{C}$, similar values to those found in the literature that were $\sim 68{ }^{\circ} \mathrm{C}$ and $\sim 127{ }^{\circ} \mathrm{C}$ [4]. The former nearly disappears and the latter narrows and shifts to $\sim 115^{\circ} \mathrm{C}$ after post-curing. The presence of two tan $\delta$ peaks can be attributed to the partial cure of the resin, whereas a single peak, i.e. only one glass transition temperature $\left(\mathrm{T}_{\mathrm{g}}\right)$ [11], suggests the complete cure of the resin, highlighting the need for post-curing. It is therefore interesting to notice that the cured resin shows a shoulder at around $60-70{ }^{\circ} \mathrm{C}$ in both DSC and DMA curves.

With post-curing, residual reactions are almost completely eliminated, avoiding adverse effects on the mechanical properties. This is ratified by the Shore D hardness values, which increased from $1.55( \pm 0.13)$ to $1.62( \pm 0.11)$ after post-curing of the Resin- $1.0 \%$ initiator sample due to increased crosslinking, i.e. the material becomes more rigid.

(a)

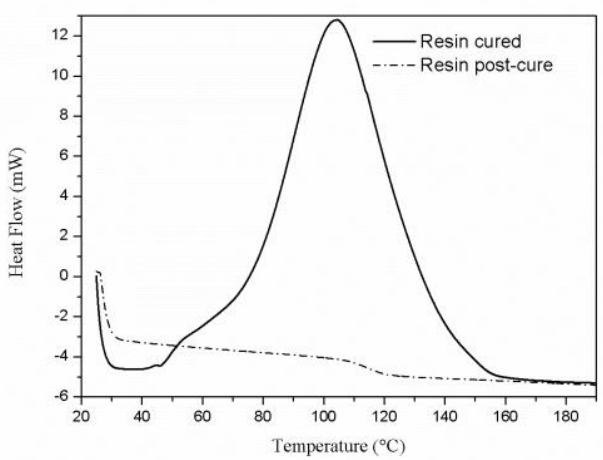

(b)

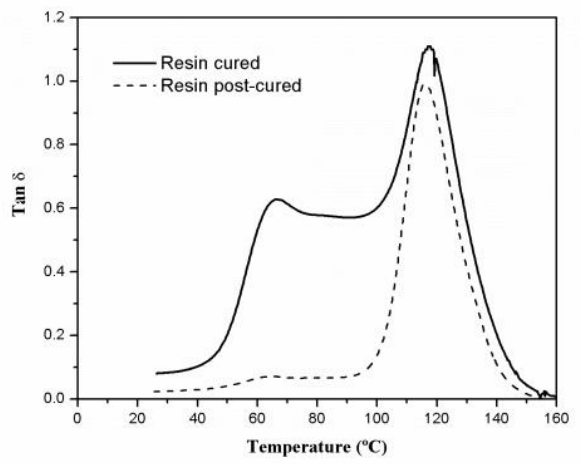

Figure 2: Characteristics of the cured and post-cured (1.0\% initiator) samples by: a) DSC and b) DMA (at $3 \mathrm{~Hz}$ ).

Table 1 compiles the results obtained with the Society of the Plastics Industry (SPI) method for all samples. Gel time decreased and the maximum curing temperature $\left(\mathrm{T}_{\max }\right)$ increased with the increase in initiator content (within 1.0-2.0\%). Gel time of a particular resin system is a very important parameter because it limits the time window for molding. Even though higher initiator content means faster curing, when this level is above $2.0 \%$, it adversely accelerates the reaction, yielding bubbles (so-called "resin boiling") and preventing complete curing. The variation in gel temperature was a little less pronounced, but also showed an increasing trend for higher P-MEK content. 
Table 1: Gel time, gel temperature and maximum curing temperature of studied systems.

\begin{tabular}{cccc}
\hline System & Gel time $(\mathrm{min})$ & $\mathrm{T}_{\mathrm{gel}}\left({ }^{\circ} \mathrm{C}\right)$ & $\mathrm{T}_{\max }\left({ }^{\circ} \mathrm{C}\right)$ \\
\hline Resin-1.0\% initiator & 36.9 & 93.8 & 138.4 \\
Resin-1.5\% initiator & 24.0 & 106.7 & 154.8 \\
Resin-2.0\% initiator & 19.7 & 104.9 & 156.5 \\
\hline
\end{tabular}

The $\tan \delta$ curves obtained by DMA at distinct frequencies for the cured Resin-1\% sample are seen in Figure 3. The E' (storage modulus) values are smaller than E' (loss modulus), knowing that $\tan \delta=\mathrm{E}$ '" E', confirming that the characteristics of an elastic solid are not reached before the gel region. Increasing the frequency leads to the increase in storage modulus (i.e. rigidity) and the shift in $\tan \delta$ to lower temperatures. It is also seen that there is a shift of $\mathrm{T}_{\mathrm{g}}$ to higher temperatures with the increase in frequency. This occurs because the greater the frequency, the more lagged response of the material when subjected to tension, because the relaxation time is longer. The other samples showed similar behavior.

The gel time of the resin can be determined by the tan $\delta$ peak maximum criterion [12]. The gel time values were within the 32 to 35 min range and the gel temperature within $115-125^{\circ} \mathrm{C}$. These values are close to those found with the SPI method (Table 1), and the difference may be due to excessive heat loss in the technique.

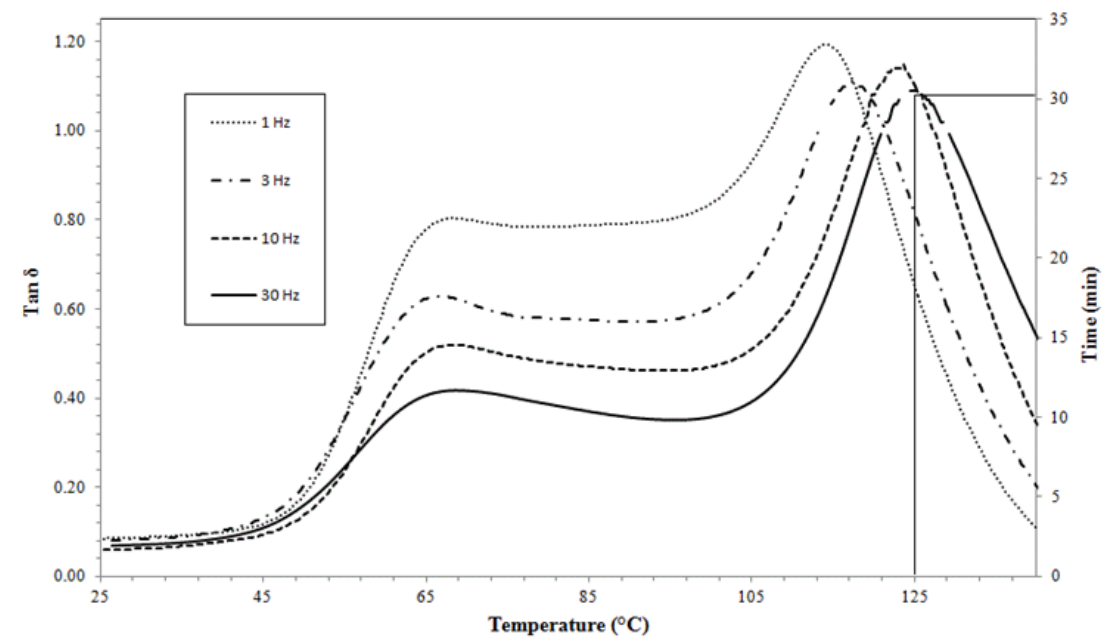

Figure 3: Tan $\delta$ curve obtained at distinct frequencies for the cured resin-1\% sample.

Density and fiber volume fraction of the composites are shown in Table 2. Density increased with fiber content due to the higher density of E-glass in comparison with the VER $\left(2.54\right.$ and $1.18 \mathrm{~g} / \mathrm{cm}^{3}$, respectively). The $\mathrm{C}_{4}$ sample, with four layers $\left(\% \mathrm{~V}_{\mathrm{f}}=16.3-17.0 \%\right)$, is almost at the limit of the so-called structural composites [13], whereas $\mathrm{C}_{6}$ sample has $\% \mathrm{~V}_{\mathrm{f}}=21.6-23.0 \%$. Fiber content directly influences the thermomechanical properties of the composite.

Table 2: Density and fiber volume fraction of composites $\mathrm{C}_{4}$ and $\mathrm{C}_{6}$.

\begin{tabular}{cccc}
\hline Composites & $\begin{array}{c}\boldsymbol{\rho} \\
\left(\mathbf{g} / \mathbf{c m}^{\mathbf{3}}\right)\end{array}$ & $\begin{array}{c}\mathbf{V}_{\mathbf{f}} \text { (Archimedes) } \\
(\boldsymbol{\%})\end{array}$ & $\begin{array}{c}\mathbf{V}_{\mathbf{f}} \text { (Burned) } \\
(\boldsymbol{\%})\end{array}$ \\
\hline $\mathrm{C}_{4}$ & 1.448 & 17.0 & 16.3 \\
$\mathrm{C}_{6}$ & 1.537 & 23.0 & 21.6 \\
\hline
\end{tabular}

The influence of post-curing on the thermo-mechanical properties of vinyl ester composites produced by RTM was investigated. Variation in storage modulus with temperature for the composites is given in Figures 4-5. Addition of the E-glass fiber reinforcement increases the storage modulus E' of the resin, that further increases with fiber content e.g. $\mathrm{C}_{4} \sim 4000 \mathrm{MPa}$ and $\mathrm{C}_{6} \sim 6200 \mathrm{MPa}$ for $0.1 \mathrm{~Hz}$, which is due to greater 
restrictions imposed by the glass fiber to the matrix movement [14]. As the temperature increases, E' decreases, with a sharp decline in the glassy region. This can be attributed to the increased molecular mobility of the polymer chains above $\mathrm{T}_{\mathrm{g}}$.

In both samples, post-curing increased storage modulus in around $40 \%$, again due to the increase in the degree of crosslinking which yields a more rigid composite. In addition, the shoulders in the DMA spectra in the viscous region (before $\mathrm{T}_{\mathrm{g}}$ ) disappeared with the post-curing (e.g. compare Figures 4a-b). The same was noted in both $\mathrm{C}_{4}$ and $\mathrm{C}_{6}$ composites. The change in DMA spectra endorsed the complete cure of the composite and the need for post-curing. The effect of frequency variation can be summarized as, at higher frequencies, the E' values are higher and the composite behaves more like a glassy material (i.e. more rigid) due to the longer relaxation times in comparison with the timescale of the experiment.
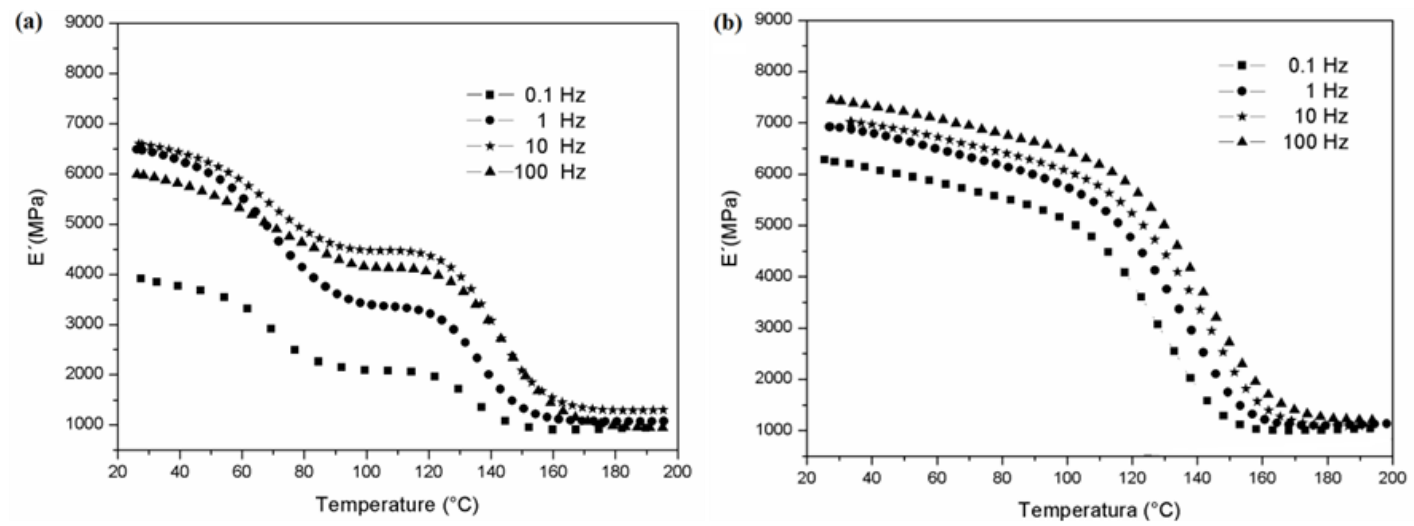

Figure 4: Storage modulus curves of the cured $\mathrm{C}_{4}$ (a) and post-cured $\mathrm{C}_{4}$ (b) composites for different frequencies.
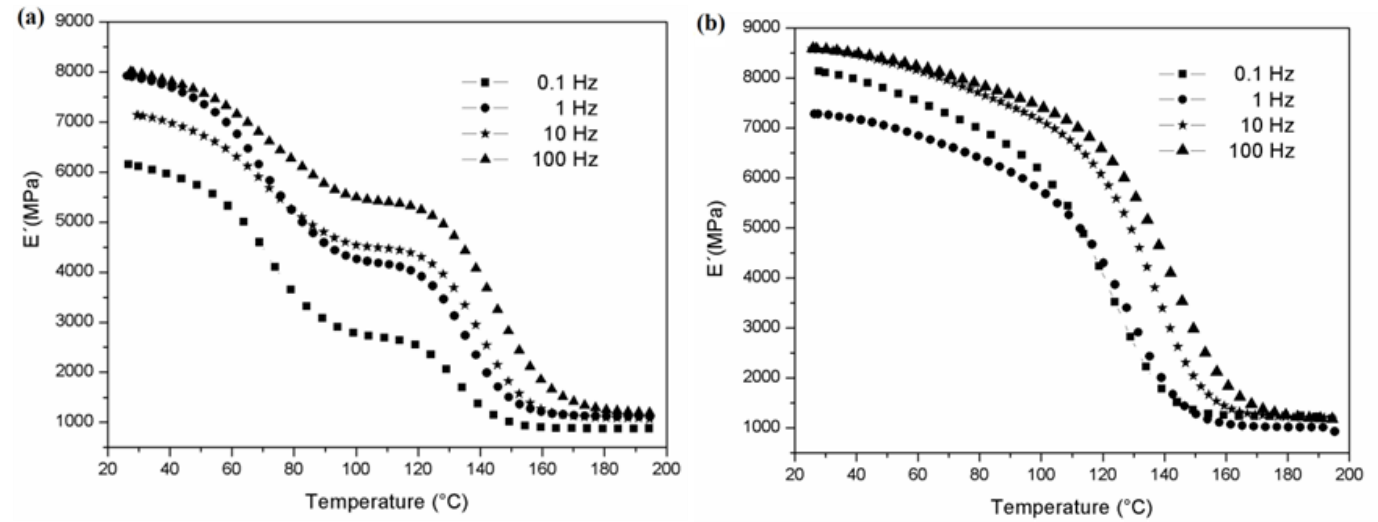

Figure 5: Storage modulus curves of the cured $C_{6}(a)$ and post-cured $C_{6}$ (b) composites for different frequencies.

Figures 6-7 shows the variation of loss modulus (E") as a function of temperature for the composites. The loss modulus evaluates the energy released by the material during cyclic loading, being mainly influenced by fiber-matrix interaction. The difference with post-curing is clear, and the difference was greater at the main peaks of the curves for example $\mathrm{C}_{4} \sim 400 \mathrm{MPa}$ and post-cured $\mathrm{C}_{4} \sim 550 \mathrm{MPa}$ for $1.0 \mathrm{~Hz}$ (Figure 6). Here again, it is seen that post-curing eliminated residual effects. For the $\mathrm{C}_{6}$ system, a distinct behavior was noticed, for example $\mathrm{C}_{6} \sim 590 \mathrm{MPa}$ and post-cured $\mathrm{C}_{6} \sim 520 \mathrm{MPa}$ for $1.0 \mathrm{~Hz}$ (Figure 7). Comparing Figures 6 and 7, the loss modulus of $\mathrm{C}_{6}$ was higher than the $\mathrm{C}_{4}$, which was attributed to greater load-transfer for higher fiber volume fraction. In addition, disappearance of the multiple shoulders in DMA spectra of the composites after post-curing endorses the final completeness of the curing reached. 

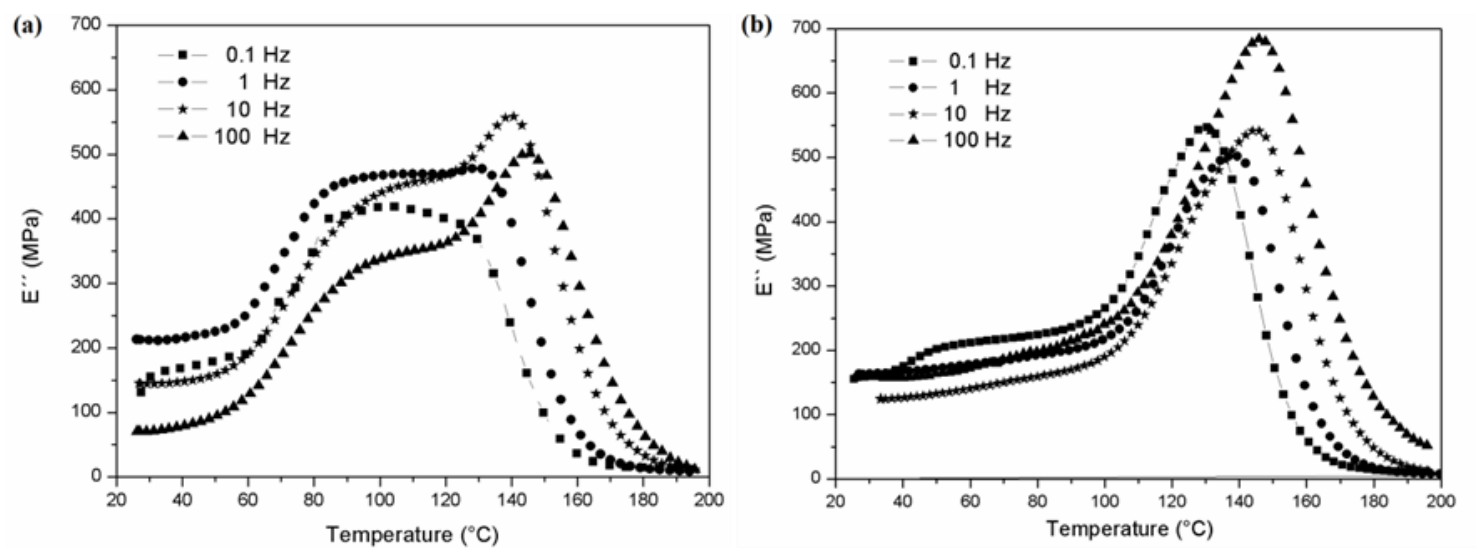

Figure 6: Loss modulus curves of the $\mathrm{C}_{4}$ (a) and post-cured $\mathrm{C}_{4}$ (b) composites for different frequencies.
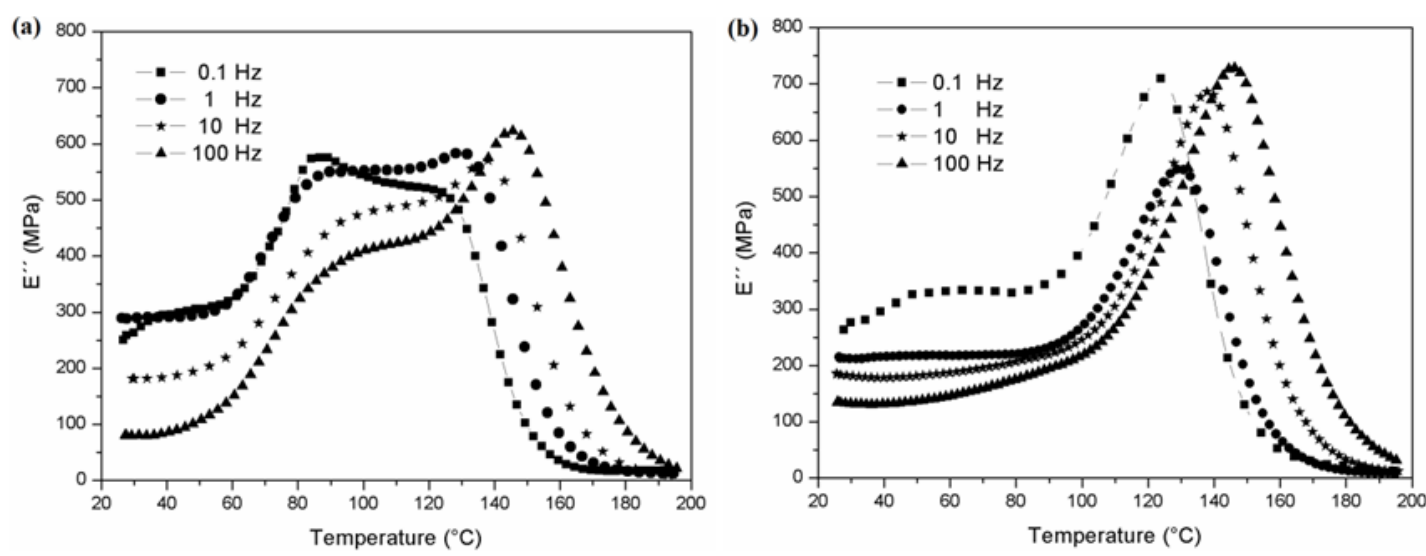

Figure 7: Loss modulus curves of the $\mathrm{C}_{6}(\mathrm{a})$ and post-cured $\mathrm{C}_{6}$ (b) composites for different frequencies.

From Figures 8-9, it is clear that there is a shift in $\mathrm{T}_{\mathrm{g}}$ to higher temperatures with increasing frequency. For example, for post-cured $\mathrm{C}_{4}$, the $\mathrm{T}_{\mathrm{g}}$ values are $140,145,150$ and $155{ }^{\circ} \mathrm{C}$, and for post-cured $\mathrm{C}_{6}$, the $\mathrm{T}_{\mathrm{g}}$ values are $130,135,145$ and $155^{\circ} \mathrm{C}$. This is because the higher the test frequency, the more lagged is the response of the material subjected to tension, as discussed above. The cured samples show two distinct peaks, one larger at $\sim 100{ }^{\circ} \mathrm{C}\left(\mathrm{C}_{4}\right)$ or $\sim 90{ }^{\circ} \mathrm{C}\left(\mathrm{C}_{6}\right)$ and another one at $\sim 135^{\circ} \mathrm{C}\left(\mathrm{C}_{4}\right)$ or $\sim 130{ }^{\circ} \mathrm{C}\left(\mathrm{C}_{6}\right)$. The lower temperature peak disappears after post-curing, leaving a single peak. Here again, the presence of two tan $\delta$ peaks can be attributed to partially cured networks, whereas a single peak indicates fully cured network [11]. In composites, this mechanical loss parameter, or $\tan \delta$, is influenced by the incorporation, type and distribution of the fibers, as well as the interaction fiber/matrix and void content. Below $\mathrm{T}_{\mathrm{g}}$, the conversion of energy is low, because, in this region, the segments of the chain are frozen, the deformations are primarily elastic and sliding of the molecules resulting in viscous flow is low [11] 

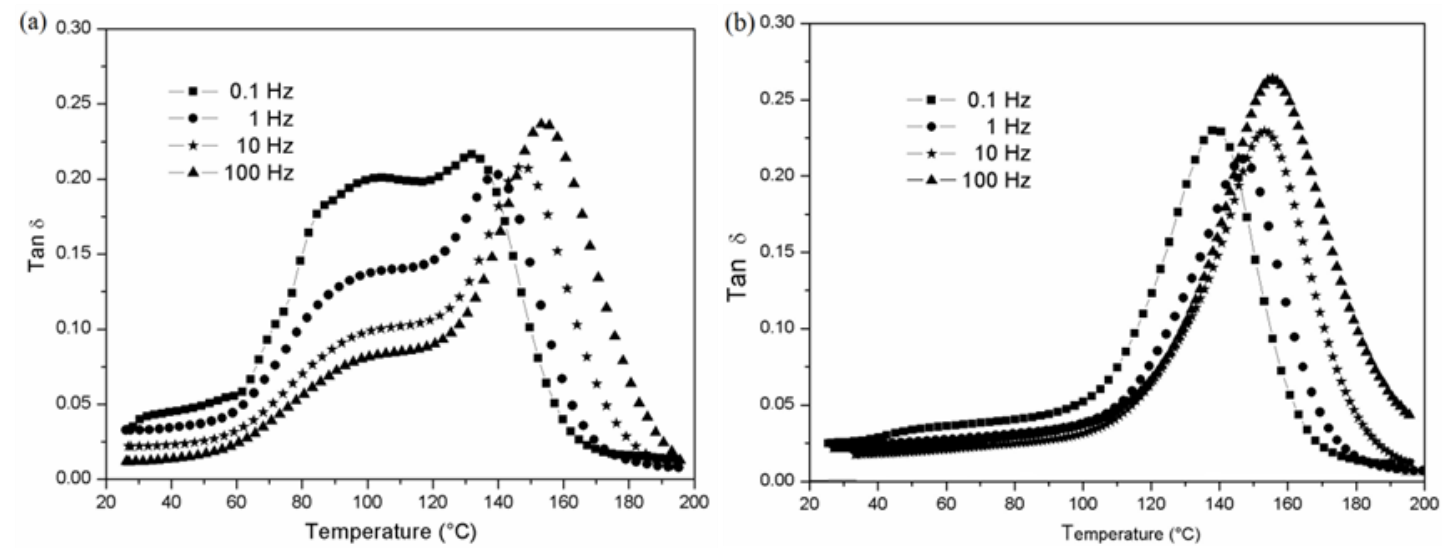

Figure 8: Tan $\delta$ curves of the $\mathrm{C}_{4}$ (a) and post-cured $\mathrm{C}_{4}$ (b) composites for different frequencies.
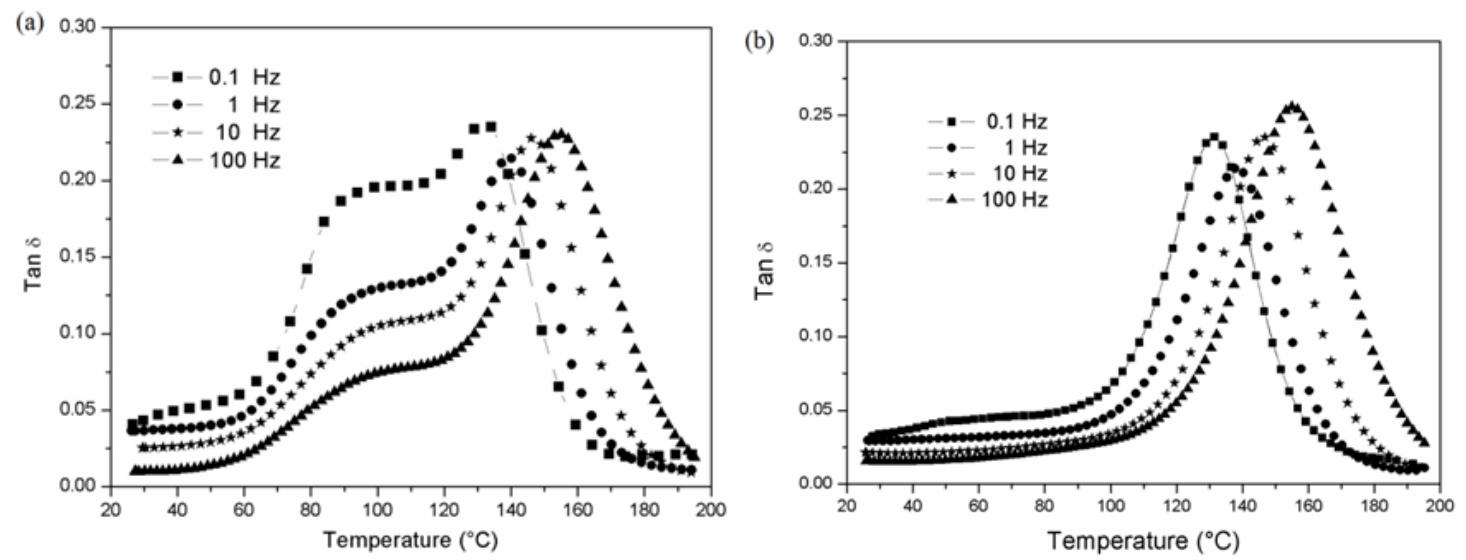

Figure 9: Tan $\delta$ curves of the $\mathrm{C}_{6}(\mathrm{a})$ and post-cured $\mathrm{C}_{6}(\mathrm{~b})$ composites for different frequencies.

\section{CONCLUSIONS}

This paper focused on the thermal-mechanical characteristics of a vinyl ester resin and composites reinforced with glass fiber using mainly DSC and DMA analyses, which were used to verify the effect of the postcuring on composite characteristics. The need for post-curing was justified, for instance, by the purge of residual enthalpy of the curing reaction and a significant increase in storage modulus (around 39\%). Postcuring increased crosslinking degree, yielding a more rigid material less susceptible to premature failure.

The gel time and gel temperature of the uncured resin were determined by the Society of the Plastics Industry (SPI) method, which is a more readily available technique than DMA, even though usually regarded as non-reliable. Nevertheless, comparison between these two methods revealed very similar results, indicating suitability of the simpler and cheaper SPI method to evaluate gel time.

\section{ACKNOWLEDGMENTS}

The authors would like to thank CNPq, CAPES and FAPERGS for the financial support.

\section{BIBLIOGRAPHY}

[1] MAZALI, C.A.I., FELISBERTI, M.I., "Vinyl ester resin modified with silicone-based additives: III. Curing kinetics", European Polymer Journal, v. 45, n. 8, pp. 2222-2233, Aug. 2009. 
[2] SULTANIA, M., RAI, J.S.P., SRIVASTAVA, D., "Studies on the synthesis and curing of epoxidized novolac vinyl ester resin from renewable resource material", European Polymer Journal, v. 46, n. 10, pp. 2019-2032, Oct. 2010.

[3] BOYARD, N., MILLISCHER, A., SOBOTKA, V., et al., "Behaviour of a moulded composite part: Modelling of dilatometric curve (constant pressure) or pressure (constant volume) with temperature and conversion degree gradients", Composites Science and Technology, v. 67, n. 6, pp. 943-954, May 2007.

[4] VISCO, A.M., CAMPO, N., CIANCIAFARA, P., "Comparison of seawater absorption properties of thermoset resins based composites", Composites Part A-Applied Science and Manufacturing, v. 42, n. 2, pp. 123-130, Feb. 2011.

[5] SCOTT, T.F., COOK, W.D., FORSYTHE, J.S., "Kinetics and network structure of thermally cured vinyl ester resins", European Polymer Journal, v. 38, n. 4, pp. 705-716, Apr. 2002.

[6] CRAWFORD, S., LUNGU, C.T., "Influence of temperature on styrene emission from a vinyl ester resin thermoset composite material", Science of the Total Environment, v. 409, n. 18, pp. 3403-3408, Aug. 2011.

[7] GARAY, A.C., HECK, V., ZATTERA, A.J., SOUZA, J.A., AMICO, S.C., "Influence of calcium carbonate on RTM and RTM light processing and properties of molded composites", Journal of Reinforced Plastics and Composites, v. 30, n. 14, pp. 1213-1221, Jul. 2011.

[8] NAFFAKH, N., DUMON, M., GÉRARD J., "Study of a reactive epoxy-amine resin enabling in situ dissolution of thermoplastic films during resin transfer moulding for toughening composites", Composites Science and Technology, v. 66, n. 10, pp. 1376-1384, Aug. 2006.

[9] ORNAGHI, H.L., SILVA, H.S.P.da., ZATTERA, A.J., et al., "Dynamic mechanical properties of curaua composites", Journal of Applied Polymer Science, v. 125, n. 2, pp. E110-E116, Sep. 2012.

[10] COOK, W.D., SCOTT, T.F., QUAY-THEVENON, S., et al., "Dynamic mechanical thermal analysis of thermally stable and thermally reactive network polymers", Journal of Applied Polymer Science, v. 93, n. 3, pp. 1348-1359, Aug. 2004.

[11] SCOTT, T.F., COOK, W.D., FORSYTHE J.S., "Effect of the degree of cure on the viscoelastic properties of vinyl ester resins", European Polymer Journal, v. 44, n. 10, pp. 3200-3212, Oct. 2008.

[12] LAZA, J.M., JULIAN, C.A., LARRAURI, E., et al., "Thermal scanning rheometer analysis of curing kinetic of an epoxy resin: 2. An amine as curing agent”, Polymer, v. 40, n. 1, pp. 35-45, Jan. 1999.

[13] GU, H., "Dynamic mechanical analysis of the seawater treated glass/polyester composites", Materials \& Design, v. 30, n. 7, pp. 2774-2777, Aug. 2009.

[14] DA SILVA, A.L.N., TEIXEIRA, S.C.S., WIDAL, A.C.C., et al., "Mechanical properties of polymer composites based on commercial epoxy vinyl ester resin and glass fiber", Polymer Testing, v. 20, n. 8, pp. 895-899, Dec. 2001. 